\title{
HERMES NO LIMBO: A HERMENÊUTICA JURÍDICA ENTRE EXCEÇÃO E APLICAÇÃO
}

\author{
Fabricio Carlos Zanin* \\ Paulo Sergio Weyl Albuquerque Costa*
}

\begin{abstract}
RESUMO
O tema é a relação entre a crítica hermenêutica do direito de Lenio Luiz Streck e o estado de exceção de Giorgio Agamben. O problema é se existe uma hermenêutica jurídica no estado de exceção? Nossa hipótese é a de que está presente uma hermenêutica jurídica existencial no estado de exceção a ser explorada desde o conceito de aplicação de Hans-Georg Gadamer. O objetivo é aproximar a hermenêutica jurídica existencial e o estado de exceção pela dimensão prática esquecida na tradição jurídica metafísica. O referencial teórico e metodológico é a hermenêutica filosófica de Gadamer e a arqueologia filosófica de Agamben.
\end{abstract}

Palavras-chave: Hermenêutica; Hermenêutica jurídica; Crítica Hermenêutica do Direito; Estado de Exceção; Aplicação.

\section{HERMES IN LIMBO: LEGAL HERMENEUTICS BETWEEN EXCEPTION AND APPLICATION}

\begin{abstract}
The theme is the relationship between Lenio Luiz Streck's hermeneutic critique of law and Giorgio Agamben's state of exception. The problem is whether there is legal hermeneutics in the state of exception? The hypothesis is that an existential juridical hermeneutic is present in the state of exception to be explored from the concept of Hans-Georg Gadamer's application. The objective is to bring existential legal hermeneutics and the state of exception due to the practical dimension forgotten in the metaphysical legal tradition. The methodologicaltheoretical frame is Gadamer's philosophical hermeneutics and Agamben's philosophical archeology.
\end{abstract}

Keywords: Hermeneutics; Legal hermeneutics; Hermeneutic Criticism of Law; State of Exception; Application

\section{INTRODUÇÃO}

\footnotetext{
* Professor Efetivo na Universidade do Tocantins - UFT. Doutorando em Filosofia do Direito na Universidade Federal do Pará - UFPA. Rua da Tobasa, 1033, Dergo, Tocantinópolis - TO, CEP: 77900-000. Email: fabriciozanin@gmail.com; Lattes: http://lattes.cnpq.br/3258935280144372; Orcid: http://orcid.org/00000003-1571-2716.

* Professor Associado da Universidade Federal do Pará - UFPA. Coordenador do Programa de Pós-Graduação da UFPA. Doutor em Direito na Pontifícia Universidade Católica - PUC/RJ. Rua Augusto Corrêa, 01, Guamá, CEP: 66075-110. Email: weylpaulo@gmail.com; Lattes: http://lattes.cnpq.br/4135075517359609; Orcid: http://orcid.org/0000-0002-8848-2950.
} 
O tema é a hermenêutica jurídica. Discute-se a relação entre a crítica hermenêutica do direito de Lenio Luiz Streck com o estado de exceção de Giorgio Agamben. O problema é se existe uma hermenêutica jurídica no estado de exceção?

Nossa hipótese é a de que está presente uma hermenêutica jurídica existencial no estado de exceção a ser explorada desde o conceito de aplicação de Gadamer. O objetivo geral é aproximar a hermenêutica jurídica existencial e o estado de exceção pela dimensão prática esquecida na tradição jurídica metafísica. O referencial teórico e metodológico é a hermenêutica filosófica de Hans-Georg Gadamer e a arqueologia filosófica de Agamben.

O texto será dividido em cinco partes: primeira, transformações da tradição hermenêutica; segunda, crise das ciências e fecundidade da hermenêutica existencial; terceira, crítica hermenêutica do direito; quarta, estado de exceção; e quinta, hermenêutica jurídica entre exceção e aplicação.

\section{TRANSFORMAÇÕES DA TRADIÇÃO HERMENÊUTICA}

O objetivo do primeiro tópico é, por um lado, apresentar a diversidade de hermenêuticas que constitui a tradição hermenêutica e, por outro, destacar os principais autores e as mudanças de concepções ocorridas ao longo do tempo. Assim, primeiro, veremos que a tradição é dividida em seis tipos: (1) exegética bíblica, (2) metodologia filológica, (3) científica geral ou universal, (4) científica metodológica das ciências humanas, (5) existencial e (6) cultural. Ademais, veremos também que, em cada tipo de hermenêutica, há autores principais: (1) Bultmann, Ebeling, Fuchs, (2) Ast, Wolf e Hirsch, (3) Schleiermacher, (4) Dilthey, (5) Heidegger e Gadamer e, por fim, (6) Ricoeur. Percebe-se, nessas transformações históricas, uma lacuna: a ausência de uma hermenêutica jurídica, que abordaremos nos tópicos seguintes.

A hermenêutica teológica de Rudolf Karl Bultmann (1999) é conhecida como "demitologização", que significa uma forma de lidar com o problema hermenêutico da relação entre a tradição do texto bíblico e o tempo atual do ser humano, destacando os elementos míticos bíblicos em seu significado original e salvívico (EILEMBERGER, 2019). Trata-se de um projeto hermenêutico de interpretação existencial, no qual, pela linguagem da Bíblia, Deus confronta o ser humano, que corresponde com a possibilidade, ou não, de autoconhecimento. No entanto, a condição para tal autoconhecimento é a compreensão histórica atual 
encontrando a compreensão textual da tradição. Entra em cena o círculo hermenêutico, no qual o ser humano está sempre no meio da história tradicional do texto que ele quer interpretar e que o significado atual do texto que ele quer interpretar está em relação com a compreensão que o ser humano tem do futuro (PALMER, 2018; GIBELLINI, 1998).

As hermenêuticas de Gerhard Ebeling (1969) e de Ernst Fuchs (1974) diferem da demitologização no sentido de que voltam sua atenção para o problema hermenêutico da relação da palavra revelada bíblica com a realidade. O evento da palavra somente pode ser comprendido enquanto experiência não somente histórica, mas também e sobretudo linguística. Através da linguagem bíblica enquanto palavra viva e evento compreensivo, o ser humano comprende, fazendo uma conexão entre a linguagem, o pensamento e a realidade. Os três autores representam uma nova hermenêutica teológica, cujos fundamentos filosóficos e existenciais estão em confronto com a exegética bíblica tradicional, que está baseada em métodos gramaticais e históricos da interpretação correta textual. Assim, a nova hermenêutica teológica é filosófica, mas a velha hermenêutica teológica é metodológica (PALMER, 2018; GIBELLINI, 1998).

A secularização da hermenêutica tradicional bíblica e de seus métodos gramatical e histórico deu origem à filologia enquanto ciência dos textos clássicos. Um exemplo disso é a hermenêutica metodológica de Friedrich Ast (PALMER, 2018), cujo principal objetivo é captar, no presente, o espírito e a unidade das obras e dos autores clássicos. Com isso em mente, divide a tarefa hermenêutica de reconstrução do processo criativo em três partes: (1) Histórica, refere-se ao conteúdo da obra; (2) Gramatical, refere-se à linguagem e (3) Autor e época, referem-se ao conceito de espírito e de gênio, pois apenas os gênios conseguem sintetizar em suas obras as ideias de uma época, as quais transcendem a temporalidade histórica. Dessa forma, vê-se que a contribuição de Ast foi dar ênfase no autor e no processo da interpretação como reconstrução do processo criativo do autor.

Herdeiro de Ast, Friedrich August Wolf (PALMER, 2018) também propõe uma hermenêutica metodológica da filologia dividida em três partes: (1) Histórica, conhecimento da época e do autor; (2) Gramática, conhecimento da linguagem; e (3) Filosófica, no sentido de que as regras da lógica podem servir de controle de consistência dos outros dois métodos anteriores. Para Wolf, a hermenêutica é a ciência das regras de reconhecimento do sentido. Logo, o objetivo da hermenêutica é não apenas captar o sentido do pensamento do autor e de sua obra, mas também comunicá-lo para outras pessoas, o que exige um esforço de diálogo e 
de empatia. Sendo assim, a compreensão do autor e da obra dirige-se a nós mesmos, enquanto a explicação dirige-se aos demais.

Eric Donald Hirsch Junior, na sua obra "Validade e interpretação" (1967), busca uma interpretação objetivamente válida e afirma que a intenção ao autor, enquanto evidência objetiva, deve ser a norma para avaliar qualquer interpretação. Para que isso seja possível, estabelece uma distinção entre significado verbal de uma passagem desde a intenção do autor e a significação atual da obra. O objetivo da hermenêutica é, segundo Hirsch, determinar as regras objetivas, imutáveis e fixas do sentido verbal da obra desde a intenção do autor. Assim, toda a complexidade do problema hermenêutico é reduzida ao sentido verbal pretendido pelo autor. A concepção do sentido verbal fundamenta-se em pressupostos filosóficos realistas, únicos possíveis para que as regras hermenêuticas sejam objetivas e imutáveis (PALMER, 2018).

A principal contribuição de Friedrich Daniel Ernst Schleiermacher (1999) é a sua concepção da hermenêutica geral e universal como ato da compreensão humana. Ela seria geral e universal porque atuaria como fundamento das hermenêuticas especiais. E seria compreendida como uma forma de superação do caráter espiritual de Ast e filosófico-lógico de Wolf, pois destaca o ser humano concreto, existente e atuante na compreensão. A tarefa hermenêutica enquanto reconstrução, mas agora baseada no círculo hermenêutico, envolve duas partes: (1) uma gramatical, dimensão das regras objetivas da linguagem da obra; e (2) outra psicológica, dimensão do pensamento subjetivo e individual. No entanto, ambas devem ser vistas no contexto mais amplo dos fatos da vida, formando uma unidade sistemática (PALMER, 2018).

A hermenêutica de Wilhelm Christian Ludwig Dilthey (2010) é a busca de uma base fundamental metodológica para as ciências humanas compreensivas, diferenciando-as das ciências naturais explicativas. Baseia-se na busca de métodos objetivos de interpretação fundamentados no tripé da experiência, da expressão e da compreensão. A experiência de vida é sempre vivida como pré-reflexiva, ou seja, anterior à relação sujeito-objeto, complementada pelas características da temporalidade. A experiência da vida sempre vivida é expressa em termos de objetificações da vida, tais como, por exemplo, as obras de arte. A compreensão é o processo de reconstrução da experiência e da expressão para encontrar o sentido, através do círculo hermenêutico (PALMER, 2018). 
Martin Heidegger (2003) transforma a fenomenologia de Husserl em uma fenomenologia hermenêutica, cuja finalidade é, a partir do círculo hermenêutico entre a questão do ser e quem faz a questão e compreende o ser, descrever e interpretar a existência desde ela mesma. Mas Heidegger não transforma apenas a fenomenologia de Husserl, transforma também o conceito de compreensão de Dilthey de duas formas: primeiro, a compreensão deixa de ser da vida para tornar-se uma estrutura fundamental da própria existência e, segundo, deixa de ser compreensão das objetificações para tornar-se ontológica. Assim, a descrição de Heidegger da existência enquanto ser-aí-no-mundo-para-a-morte destrói as fundamentações epistemológicas das ciências e das hermenêuticas tradicionais metodológicas, atentando para um modo mais radical, original, fundamental, constitutivo, existencial, prático e pré-científico de relação com o mundo, com os outros e com nós mesmos (STEIN, 2011).

Nas trilhas do pensamento de Heidegger, sobretudo depois da reviravolta em sua filosofia para a história do ser como acontecimento linguístico, Hans-Georg Gadamer (1997) criou sua hermenêutica filosófica. Nela, Gadamer destrói as teorias tradicionais da estética, das ciências humanas históricas e da linguagem, afirmando que tais teorias metodológicas escondem a experiência hermenêutica da verdade da arte, das ciências humanas e da linguagem. Foi com o própósito de recuperar as experiências de verdade não metodológicas que criou sua hermenêutica filosófica, cujos conceitos principais são: compreensão, preconceitos, autoridade, tradição, círculo hermenêutico, fusão de horizontes, diálogo, jogo e linguagem. Após sua obra principal, deu ênfase às hermenêuticas aplicadas enquanto razão hemenêutica prática (PALMER, 2018; LAWN, 2007; KAHLMEYER-MERTENS, 2017; SCHMIDT, 2012).

Paul Ricoeur (1978) é um dos principais representantes da hermenêutica da desconfiança, da dúvida ou da suspeita, pois, amparado em Marx, Nietzsche e Freud (FOUCAULT, 1980), define a hermenêutica como um processo de decifração que vai de um significado manifesto a um significado latente. Essa definição de hermenêutica esclarece a própria estrutura do mito e do símbolo enquanto que, por um lado, mostram algo manifesto, mas, por outro, escondem algo latente e oculto. Tal hermenêutica é desmitificadora no sentido de que acaba com máscaras, ilusões e mentiras que se mostram, pois acessa o significado verdadeiro que foi mascarado, ilusionado e mentido. A desmitificação é diferente da 
demitologização exatamente nesse sentido, pois a primeira destrói os símbolos e mitos, enquanto a segunda visa torná-los vivos para a atualidade (PALMER, 2018).

Cumpre-se, assim, o objetivo desse primeiro tópico, que era apresentar os tipos de hermenêuticas, seus autores e suas transformações ao longo do tempo. Percebe-se que a hermenêutica nasceu metodológica vinculada a textos e para encontrar a interpretação correta, como vimos na exegese bíblica e na filológica. Com Schleiermacher, a hermenêutica começa a tematizar o autor, indo além do texto. Com Dilthey, vai-se além do autor e do texto, entendidos que são como expressões da vida. Com Ricoeur, torna-se cultural e simbólica no sentido da suspeita e da desconfiança. Porém, definitivamente, é apenas com Heidegger e com Gadamer que a hermenêutica atinge seu apogeu, pois se torna existencial, no primeiro, e, no segundo, filosófica, sendo eles os fundamentos da nova hermenêutica teológica (Bultmann, Ebeling, Fuchs). Assim, é com eles, Heidegger e Gadamer, que vamos aos próximos tópicos em busca de preencher a lacuna da inexistência de uma hermenêutica jurídica.

\section{CRISE DAS CIÊNCIAS E FECUNDIDADE DA HERMENÊUTICA EXISTENCIAL}

Com base na hemenêutica existencial de Heidegger e de Gadamer vista no tópico anterior, agora veremos como é possível que tal posição permita uma crítica destrutiva da visão tradicional tanto da filosofia, como do direito. Para isso, dividimos a apresentação em quatro partes: (1) Heidegger e sua obra "Introdução à filosofia" (1999); (2) Bornheim e sua obra de introdução existencial à filosofia (2003); (3) Martins e sua interpretação existencial do direito (2018); e (4) outra posição existencial sobre o direito chamada de pós-positivista (ABBOUD, CARNIO, OLIVEIRA, 2019). Assim, percebe-se a fecundidade de tal referencial teórico-filosófico e seu potencial crítico-destrutivo de concepções tradicionais e, ao mesmo tempo, construtivo de alternativas. Portanto, se a estrutura filosófica e científica - baseada em sujeito, objeto, método, verdade e fundamento - entra em crise, a hermenêutica existencial oferece alternativas.

Na sua obra "Introdução à filosofia", Heidegger (1999) afirma que a maioria das introduções à filosofia fracassa porque está baseada em um equívoco. Fundamenta-se na estrutura epistemológica das ciências e da filosofia, ou seja, sujeito, objeto, método, verdade e fundamento. Assim, primeiro, parte do equívoco básico de que nós, aqueles que devemos ser introduzidos na filosofia e enquanto sujeitos, estamos situados fora e distantes dela. E, 
segundo, assume que a filosofia enquanto objeto diferente do sujeito, deve ser acessada a partir do uso de um método, ou, dito de outra forma, nós, sujeitos, devemos seguir o caminho de um método para conseguirmos nos introduzir na filosofia. A verdade aí, nessa relação entre sujeito, objeto e método, será a correspondência entre pensamento e realidade, e todos os elementos da estrutura estarão fundamentados na razão do sujeito pensante (epistemologia).

Obviamente, Heidegger é crítico desse equívoco básico das obras de introdução à filosofia. E, mais ainda, enfrenta a estrutura epistemológica das ciências e da filosofia na analítica existencial de sua obra "Ser e tempo" (2003). O sujeito é substituído pelo Dasein (ser-aí). O objeto é substituído pela ocupação prática do ser-aí com a instrumentalidade dos entes subsistentes. A relação metodológica com a realidade é substituída pela estrutura do Dasein como ser-aí-no-mundo-com-outros-para-a-morte. A verdade como correspondência, adequação e representação é substituída pela verdade como alétheia (des-velamento). E o fundamento torna-se ontológico. A partir dessa revolução do giro ontológico heideggeriano, estamos já na filosofia porque a filosofia está em nós e pertence a nós no sentido de que já sempre filosofamos. Ser humano - existir! - significa já filosofar. E filosofar é colocar a filosofia em movimento na existência.

Na sua obra "Introdução ao filosofar", Bornheim (2003) afirma que o fundamento do filosofar é a existência e sua atitude filosófica inicial da admiração. Nesse sentido, a filosofia começa na atitude existencial do filósofo ao filosofar. O fundamento existencial do filosofar também destrói a ideia da metafísica da subjetividade e seu fundamento subjetivo e racional do "pai da modernidade" Descartes. No entanto, há todo um itinerário existencial a ser cumprido para que a filosofia tenha início, que é dividido em três partes: (1) admiração ingênua: caracterizada pela postura dogmática, há uma indiferença ontológica entificadora, uma vez que o ser humano está dissolvido no mundo, na realidade, nas coisas, nos objetos; (2) experiência negativa: aqui acontece o inverso da admiração ingênua, pois, mesmo admitindo uma separação relacional com o mundo, o mesmo é negado e perde seu sentido, resultando no egocentrismo entificador; e (3) conversão filosófica: recuperação da distância do ser humano com o mundo, mas, ao mesmo tempo, preservando o aspecto relacional e participativo do ser humano com o mundo a partir da diferença ontológica e do círculo hermenêutico (HEIDEGGER, 2003).

Heidegger é o filósofo do ser porque recuperou a questão do ser esquecida pela tradição filosófica. Ao recolocar a questão do ser, afirmou que o ser não é ente, mas que, ao 
mesmo tempo, o ser só é ser de um ente e o ente só é ente no seu ser. Eis, respectivamente, a diferença ontológica e o círculo hermenêutico (STEIN, 2002). Toda a metafísica ocidental é indiferença ontológica ou onto-teo-lógica no sentido de tratar o ser como ente, como algo entificado. A existência é o modo de ser do ente que nós somos. O ente que nós somos tem seu ser aí no mundo. Assim, na conversão filosófica, entende-se porque o ser humano é diferente do mundo, mas, a partir da diferença ontológica, eles acontecem junto como ser-nomundo. Se o ser da diferença ontológica pode ser esquecido ou entificado, o mesmo pode acontecer com o ser humano na relação com o mundo, indo na direção ou do dogmatismo ou da experiência negativa. A todo instante e em cada caso, por existir a possibilidade de perderse no dogmatismo ou no egocentrismo, a relação de ser humano com o mundo a partir da diferença ontológica e do círculo hermenêutico é, para Bornheim, um mistério (abertura) que, se não for preservado e cuidado será sempre entificado (BORNHEIM, 2003).

Na conclusão de sua obra, Bornheim afirma que:

(...) o homem não é a medida do homem, pois a fidelidade à sua própria essência só
é compatível com um comportamento cujas raízes se encontram no sentido de
abertura, de disponibilidade, de consentimento admirativo ao ser. Consentindo ao
ser, realiza-se o homem como liberdade e como inteligência. O ser é, pois, a medida
do homem e do filosofar" (2003, p.135).

É nítida a semelhança entre o filosofar de Heidegger e o filosofar de Bornheim, no sentido de reconhecer a diferença ontológica e o círculo hermenêutico. No apêndice da obra, intitulado "Filosofia e sistema" (BORNHEIM, 2003, p.137-152), o autor afirma que não se deve fundamentar o sistema dedutivamente a partir do ente, mas sim de pensar sua possibilidade a partir da diferença ontológica, que reconhece a existência como ser no mundo.

Na sua obra "Ciência do direito e hermenêutica", Martins (2018), apoiando-se não apenas na obra "Introdução à filosofia" de Heidegger, que já vimos, mas também em Gadamer, ambos representantes da hermenêutica existencial, propõe uma nova fundamentação existencial da ciência do direito. Para isso, mostra a denúncia de Heidegger da crise das ciências exposta em três partes: (1) crise da estrutura interna das ciências; (2) crise da ciência enquanto posição no todo cultural da existência do ser humano; (3) crise da ciência enquanto relação com a existência do ser humano. A primeira mostra que, mesmo com as crises dos fundamentos das ciências, elas continuarm progredindo. A segunda mostra que, mesmo as ciências sendo questionadas em suas pretensões técnicas, elas continuam sendo 
popularizadas na forma de tecnologias e de manuais, resumos, compêndios e facilitações. A terceira mostra que, mantendo as ciências sua estrutura epistemológica, elas excluem a diferença ontológica e o círculo hermenêutico, entificando a existência, o mundo e o tempo histórico.

Heidegger afirma que a história da metafísica como esquecimento do ser (entificação) é resumida na expressão "onto-teo-logia" (2000). Tatián (1997) complementa com a expressão "onto-teo-tecno-logia". Martins (2018) afirma que a história da ciência do direito segue essa mesma lógica metafísica enquanto onto-teo-tecno-logia. A ontologia da onto-teotecno-logia refere-se à ontologia clássica objetivista e cosmológica enquanto fundamento do direito natural antigo. A teologia da onto-teo-tecno-logia refere-se à ontologia medieval objetivista e teológica enquanto fundamento do direito natural divino. Por fim, a tecnologia da onto-teo-tecno-logia refere-se à ontologia humanista e racionalista enquanto fundamento do direito natural moderno, cujo resultado maior é a tradição do positivismo jurídico. Nas duas primeiras, direito, ética e política estavam e manifestavam-se todos juntos na razão prática, mas, na última, tudo é separado, ordenado, controlado, especializado e disciplinado na razão teórica.

A ciência do direito positivista fundamentada no direito natural moderno, humanista e racionalista, ao separar direito, ética e política, acaba por ser atingida pelas crises das ciências em suas três características. A proposta de Martins, baseada na hermenêutica existencial de Heidegger e Gadamer, é justamente recuperar novamente o que foi esquecido na tradição jurídica, isto é, a existência, o mundo, a história, a ética e a política, que acontecem na experiência da verdade como des-velamento, que preserva a diferença ontológica e o círculo hermenêutico. Assim, do mesmo modo que no filosofar de Bornheim o mistério da diferença ontológica deve ser preservado na relação entre o ser humano e o mundo, a racionalidade prática existencial deve ser recuperada no direito para preservar a abertura da interpretação na relação da norma com o caso. Portanto, Gadamer defende que a tarefa da hermenêutica jurídica seria a de criar uma ponte entre as regras jurídicas e os casos particulares. Mas o espaço entre a regra jurídica e o caso particular é insuperável, restando o espaço de jogo presente em todas as operações das ciências humanas enquanto reconectadas com a racionalidade prática (MARTINS, 2018, p.179).

Na obra "Introdução ao direito", Abboud, Carnio e Oliveira (2019), seguindo o mesmo critério onto-teo-tecno-lógico na história da ciência jurídica, apresentam, para os limites do 
que nos interessa aqui, três definições de direito: (1) definição jusnaturalista, (2) definição juspositivista e (3) definição pós-positivista. Chega-se, na definição juspositivista, à mesma conclusão que vimos anteriormente de, por um lado, esquecimento entificador da existência, do mundo, da história e, por outro, de separação teórica entre direito, ética e política. Assim, o positivismo tem uma visão insuficiente (entificadora!) do fenômeno jurídico, uma vez que desconsidera a prática jurídica interpretativa, relegando-a à discricionariedade. Já na definição juspositivista, o direito é visto partir da racionalidade prática hermenêutica, na qual o fenômeno jurídico é visto de forma mais ampla e interpretativa, desde a verdade como desvelamento.

Nessa introdução ao direito, portanto, aproxima-se a interpretação do direito do que vimos na introdução ao filosofar de Bornheim, na introdução à filosofia de Heidegger e no espaço de jogo hermenêutico prático entre regras e casos de Gadamer. O direito e o interpretar, por um lado, a filosofia e o filosofar, por outro, são vistos desde bases existenciais e hermenêuticas. Assim, "a hermenêutica foi alçada, de mera disciplina auxiliar das ciências do espírito (Schleiermacher/Dilthey) para condição de Filosofia, fundamentada na existência e sendo percebida em seus vínculos (antropológicos) com a práxis (Heidegger/Gadamer)" (ABBOUD, CARNIO, OLIVEIRA, 2019, p.160).

Acredita-se que a fecundidade da hermenêutica existencial foi apresentada de modo satisfatório em todo seu potencial crítico-destrutivo e, ao mesmo tempo, construtivo. Assim, a interpretação jurídica pode ser, primeiro, considerada como aplicação, no sentido de sempre relacionar, no espaço do jogo, não apenas a regra com o caso, mas, também, segundo, o ser humano com o mundo. A recuperação do caráter prático do direito depende da manutenção, em todo caso e em cada instante, do mistério da abertura e revelação dessas relações do ser humano com o mundo e com o direito (verdade como des-velamento, diferença ontológica e círculo hermenêutico). No entanto, acreditamos que a fecundidade da hermenêutica existencial ainda pode ser mais explorada a partir da Crítica Hermenêutica do Direito, de Streck (2017), como modo preparatório da problematizalçao que faremos do Estado de Exceção, de Agamben e do conceito de "hermenêutica jurídica da exceção" em direção ao preenchimento da lacuna da inexistência da tematização de uma hermenêutica jurídica.

\section{CRÍTICA HERMENÊUTICA DO DIREITO}

Rev. de Argumentação e Hermenêutica Jurídica | e-ISSN: 2526-0103 | Evento Virtual | v. 6 | n. 1 | p. 37-59 | Jan/Jun. 2020 
Com base nas transformações da hermenêutica, na crise das ciências e nos exemplos da fecundidade da hermenêutica existencial seja na filosofia, seja nas ciências, vamos agora explorar um pouco mais tal fecundidade na obra "Hermenêutica jurídica e(m) crise", de Streck (2014). Se a obra "Verdade e método", de Gadamer (1997), tem uma tripla estrutura de arte, ciências e linguagem, na qual destrói criticamente e reconstrói existencialmente seus alvos, a obra de Streck, "Verdade e Consenso" (2017) também pode ser lida do mesmo modo, pois sua proposta é de destruição e reconstrução das crises da ciência jurídica (do estado, do judiciário), do ensino jurídico e da linguagem (da interpretação). Vejamos, então, a partir de agora, como o autor faz sua proposta e denuncia os seus obstáculos.

Acreditamos que a obra mais importante de Streck seja sua "Hermenêutica jurídica e(m) crise" (2014). Todas as outras são derivações e aprofundamentos desta obra principal e de suas ideias. Nela, o autor propõe uma hermenêutica jurídica e filosófica crítica, baseada em três pilares: (1) uma nova relação entre direito e filosofia; (2) interpretação do fenômeno jurídico e de sua ciência numa perspectiva histórica dentro da tradição jurídica (onto-teotecno-logia); e (3) denúncia da teoria jurídica predominante na ciência jurídica atualmente: o positivismo jurídico. Assim, o direito não é capaz de sozinho, pensar a si mesmo, exigindo o contato com outras ciências e com a filosofia. Ademais, somente uma perspectiva temporal e histórica é capaz de ver que o fenômeno jurídico nem sempre foi entendido apenas de modo positivista.

A obra (2014) começa denunciando um dualismo na ciência do direito que é derivado de um dualismo metafísico. A primeira parte do dualismo científico é o mundo abstrato das normas jurídicas, que formam o sistema jurídico. A segunda parte é o mundo concreto dos fatos sociais, dos atos sociais, da vida humana, da existência. Absolutamente todos os dualismos da ciência jurídica, como, por exemplo, o de questão de direito (nomos) e questão de fato (anomos), derivam desse entre mundo normativo e mundo fático. Já o dualismo metafísico se dá entre o mundo sensível e o mundo inteligível, cujo representante maior é o mito da caverna de Platão ou, outro exemplo, o dualismo cartesiano entre sujeito e objeto. Todo dualismo, seja científico ou metafísico, é acompanhado do problema de sua relação ou da passagem de um para o outro, o espaço do jogo. Não por acaso Hermes é o símbolo da hermenêutica por transitar entre esses dois mundos (no seu caso, o divino e o humano).

Para Streck (2014), o dualismo científico entre mundo normativo e mundo fático é a razão das crises enfrentadas pelo direito: da ciência jurídica, da dogmática, do estado, do 
judiciário, da política, da linguagem, da interpretação, dentre outras. Da mesma forma, o dualismo metafísico entre mundo sensível e mundo inteligível ou entre mundo do sujeito e mundo do objeto acabam gerando crises: crise de fundamentos, crise paradigmática, crise da modernidade. As crises da ciência jurídica juntas com as crises da metafísica formam o que ele chama de crise de dupla face. O conceito de sentido comum teórico dos juristas utilizado por Streck resume, na operacionalidade do direito, as crises do direito. E a crise de fundamentos resume as crises dos dualismos metafísicos. Logo, se o dualismo metafísico fundamenta o dualismo jurídico, então a crise de fundamentos legitima o sentido comum teórico dos juristas. A história da ciência jurídica enquanto onto-teo-tecno-logia, que vimos anteriormente, pode ser entendida como crise de fundamentos da ciência jurídica.

Se a crise de dupla face é sintetizada no conceito de sentido comum teórico dos juritas, precisamos decifrá-lo para entender as causas das crises jurídicas e das crises de fundamentos. O senso comum é tradicionalemnte entendido como um obstáculo ao conhecimento científico, pois se baseia na reprodução irrefletida de preconceitos ao invés da produção refletida de conceitos. A novidade conceitual aí, no senso comum teórico, está na possibilidade de um senso comum justamente onde ele não deveria existir, na teoria científica, pois deveria estar superado. Assim, o sentido comum teórico dos juristas nada mais é do que a reprodução irrefletida de preconceitos teóricos, no caso da ciência jurídica, a reprodução não refletida da teoria jurídica dominante positivista, o que acaba mantendo a distância entre mundo normativo e mundo fático e reproduzindo inefetividade, desigualdade e injustiça.

Se o senso comum teórico dos juristas reproduz, de forma irrefetida, a teoria dominante positivista, deve-se entender as transformações históricas do positivismo (STRECK, 2014, 2017, 2018). Assim, a crítica hermenêutica do direito interpreta o fenômeno jurídico numa perspectiva histórica dentro da tradição jurídica (onto-teo-tecno-logia), o que permite entendermos que há vários tipos de positivismos. Daremos destaque a dois, por serem mais extremos em suas proposições e consequências, o positivismo exegético e o positivismo normativista. Ambos têm em comum a proposição de que o fenômeno do direito deve ser entendido separado da moral. E ambos têm como consequências, sobretudo no âmbito da interpretação, a ocorrência de discricionariedades, que podem ser entendidas como esquecimento da dimensão prática do direito que já vimos anteriormente. 
Para entender os dualismos científicos jurídicos, o sentido comum teórico dos juristas e as consequências hermenêuticas discricionárias das teorias positivistas na interpretação, Streck usa o conceito de sincretismo da dogmática jurídica. De um lado, temos a metafísica clássica e sua ontologia objetivista do mito do dado ou do objeto, o qual, aplicado ao direito, resulta no dogma da lei do positivismo exegético, fundamentando o voluntarismo legislativo. De outro lado, temos a metafísica moderna e sua ontologia subjetiva como fundamento do conhecimento certo e seguro. Trata-se do mito do sujeito, o qual, aplicado ao direito, resultado no dogma da decisão do positivismo normativista, fundamentando o voluntarismo judiciário. O problema é que a dogmática jurídica reproduz, de forma irrefletida (senso comum teórico), ambos os positivismos, consolidando, num mix metafísico, de forma oportunista, conveniente e cínica, ainda mais inefetividade, desigualdade e injustiça.

Segundo Streck (2014), na crise da ciência jurídica entre o positivismo exegético da vontade da lei (do legislador) e o positivismo normativista da vontade da decisão (do juiz) há um beco sem saída. Da mesma forma, na crise de fundamentos entre a metafísica do objeto (ontologia clássica e medieval) e a metafísica do sujeito (ontologia moderna) há um beco sem saída. O caráter sem saída do beco fica ainda maior quando o sentido comum teórico do jurista reproduz, de forma sincrética, um ou outro positivismo nas suas interpretações. No entanto, o autor propõe uma alternativa à crise de dupla face: sua crítica hermenêutica do direito, baseada na hermenêutica jurídica e filosófica crítica, cujo referencial teórico é a hermenêutica existencial que vimos nos tópicos anteriores em toda sua fecundidade.

A hermenêutica tradicional metodológica tem quatro características: (1) é descritiva; (2) é teórica; (3) prescritiva e (4) textual. Descritiva por que descreve o ato e o processo da interpretação. Teórica porque adota uma perspectiva científica sobre a interpretação, baseada na estrutura epistemológica que vimos anteriormente de sujeito, objeto, método, verdade e fundamento. É prescritiva no sentido de que determina métodos, regras e procedimentos para a interpretação correta, certa e segura. Interpretação correta de quê? De textos. Essas características manifestam-se em todas as hermenêuticas especiais (bíblica, filológica, jurídica, literária), cujo representante maior é Betti (2007). No entanto, como vimos, Schleiermacher propôs uma hermenêutica geral ou universal com base na compreensão. No entanto, além dessas hermenêuticas (as especiais e a universal), há a hermenêutica existencial, fundamental ou filosófica. 
Para comprovar a importância destrututiva e construtiva da hermenêutica existencial, fundamental e filosófica de Heidegger e Gadamer, Streck percorre toda a história da linguagem, passando pelos seguintes autores ou escolas: Platão, Aristóteles, estoicismo, Agostinho, nominalismo, Descartes, Kant, Nietzsche, Hamann, Herder, Humboldt, Saussure, Peirce, Lacan, semiótica jurídica (sintaxe, semântica, pragmática), neopositivismo lógico, Wittgenstein e Austin. Qual sua conclusão de todo esse percurso? A de que, com a hermenêutica existencial, a linguagem torna-se constitutiva, o logos hermenêutico fundamenta o logos apofântico e a interpretação é explicitação da compreensão na aplicação.

Logo, vemos que a fecundidade da hermenêutica existencial está em justamente recuperar, destrutiva e construtivamente, o que a metafísica e as ciências tradicionais esquecem e propor um direito efetivo, igual e justo (hermenêutica jurídica da aplicação)!

Assim, o objetivo da crítica hermenêutica do direito é uma nova dogmática, na qual ocorra uma mudança radical do sentido comum teórico dos juristas e seja possível uma nova compreensão do direito que seja efetivo, igual e justo. Mas os obstáculos são grandes, pois a velha dogmática, fundamentada no sentido comum teórico dos juristas, cuja compreensão inautêntica e ilegítima reproduz a crise de dupla face, baseia-se na manutenção da inefetividade, das desigualdades e das injustiças (hermenêutica jurídica da exceção).

Em todo caso e a cada instante, o jurista - que se encontra no mesmo espaço de jogo onde Hermes habita - deve decidir, nessa luta do novo (hermenêutica existencial da aplicação) contra o velho (hermenêutica metodológica da exceção), onde posicionar-se. A função da crítica é justamente fazer o velho ver o novo e tornar o novo possível. Somente desse modo, o direito recupera sua dimensão transformadora e utópica de justiça, igualdade e efetividade, na qual os direitos humanos desempenham papel essencial.

Concluímos, assim, os exemplos da fecundidade da hermenêutica existencial no preenchimento da lacuna da hermenêutica jurídica na tradição das hermenêuticas. Vimos sua relação com a filosofia (HEIDEGGER e BORNHEIM) e com o direito (MARTINS; ABBOUD, CARNIO, OLIVEIRA e STRECK).

O que podemos reconhecer de comum em todas essas propostas é a recuperação do que a metafísica havia esquecido, excluído, separado. Assim, a existência, o tempo, o mundo, a prática são, ao mesmo tempo que elementos recuperados na denúnica dos limites da filosofia e das ciências tradicionais, também propostas para que as mesmas se transformem e 
se tornem melhores e mais completas, fundamentadas numa metafísica finita (verdade como des-velamento, diferença ontológica e círculo hermenêutico).

Em obras mais recentes, Streck $(2017 ; 2018)$ tem-se utilizado do conceito de "estado de exceção hermenêutico". Com a finalidade de entender melhor o uso que ele faz de tal conceito, vamos avançar aos próximos tópicos.

\section{ESTADO DE EXCEÇÃO}

A obra "Estado de exceção", de Agamben (2004), é dividida em seis partes: (1) estado de exceção como paradigma de governo; (2) força de lei; (3) iustitium; (4) luta de gigantes acerca de um vazio; (5) festa, luto e anomia; e (6) auctoritas e potestas. Para os objetivos relevantes aqui, serão destacados os dualismos principais presentes em algumas dessas partes e a experiência limite realizada por Agamben a partir do estado de exceção. A experiência limite é utilizada como um caminho destrutivo e metodológico pelo autor no sentido de aproximar os dualismos metafísicos, quase confundi-los, numa experiência de in-distinção. Em razão dessa estratégia, o grau de dificuldade da obra é inversamente proporcional ao seu pequeno tamanho. As tentativas de aproximar a hermenêutica existencial da ciência jurídica destacaram a necessidade de ampliar o jurídico, recuperando tradições práticas dela esquecidas. Agamben também pode nos ajudar nisso.

Agambem começa sua obra (2004) afirmando que há uma lacuna teórica a respeito do estado de exceção como genuíno problema jurídico. Essa falta acaba gerando não apenas problemas de compreensão do estado moderno, nacional e soberano, mas também os dualismos de questão de fato (político) e questão de direito (jurídico), que geram problemas de aplicação, como vimos na Crítica Hermenêutica do Direito. Para encontrar essa teoria adequada do estado de exceção, ele faz a experiência limite da relação direito e política a partir do jogo da diferença (ontológica?), perguntando-se o que é uma ação política-jurídica? Ao problematizar a experiência limite no nazismo e nos Estados Unidos da América, conclui que a exceção se tornou paradigma de governo na política contemporânea, causando deslocamentos constitucionais.

Ao diferenciar o estado de exceção real como sendo militar e ocorrendo num tempo anormal e transitório, Agamben (2004) diz que o estado de exceção se tornou paradigmático em razão de sua transformação fictícia, via decisão política e soberana, e sua permanência no 
tempo de normalidade. Além do jogo da diferença que aproxima, na experiência limite, direito e política, também a biopolítica da vida nua faz tal aproximação, pois, ao mesmo tempo em que o direito se refere à vida, suspende-a, abandonando-a à decisão soberana de vida ou de morte.

Nesse sentido é que o conceito de estado de exceção é descritivo de um conjunto de fenômenos jurídicos que, enquanto jogo da diferença, é o nome dado a experiências limites de, ao mesmo tempo, referência (inclusão) e suspensão (exclusão). Guerra civil, resistência, necessidade, nazismo, totalitarismo, democracia, emergência, urgência, leis marciais, poderes especiais, vida nua, dentre outros - inclusive a pandemia do coronavírus (AGAMBEN, 2020) -, são alguns exemplos dessas experiências limite jurídicas que, a partir do jogo da diferença, o aproximam da política. O império romano e o direito romano, a igreja e o direito canônico e o estado moderno e o direito positivo estão cheios desses exemplos, que o autor faz questão de explorar.

Para exemplificar a lacuna teórica acerca do estado de exceção, Agamben (2004) dá dois exemplos. O primeiro é a diferença entre os ordenamentos jurídicos que tentam regular a exceção (atos de governo fora da lei são legais) e outros que não tentam regular a exceção (atos de governo fora da lei são ilegais). O segundo exemplo refere-se às teorias da necessidade objetiva (como fonte do direito) e subjetiva (como caso de lacuna fática além do direito). Sua conclusão é a de que a teoria e a compreensão adequadas do estado de exceção é uma disputa sobre o seu lugar, pois não é dentro nem fora do direito e não é objetivo nem subjetivo.

O que realmente está em jogo no estado de exceção é, segundo Agamben (2004), o problema do significa jurídico de uma ação política, que as cortes supremas do mundo inteiro vivenciam todos os dias. O exemplo da necessidade pode esclarecer o que está em jogo. Partese do princípio de que a necessidade não tem lei. Sendo assim, por um lado, a necessidade não reconhece nenhuma lei e muitas coisas são feitas contra a lei. Mas, o ilícito não é considerado um ilícito, pois acontece a subtração ou dispensa de um caso com relação à aplicação da lei. Por outro lado, a necessidade cria sua própria lei, sendo originária, revolucionária e violenta. No entanto, é uma violência ilegal que se torna legal, pois o direito é eliminado e dispensado no fato. 
Entre o mundo jurídico da norma e o mundo real da aplicação existe um espaço de jogo da diferença onde acontece a experiência da exceção. Nesse espaço de suspensão do direito, há duas possibilidades. Na primeira, suspende-se o direito para manter o direito. Essa experiência paradoxal também é possível com a constituição, com a democracia e com os direitos fundamentais, como nas nossas experiências do estado de defesa e de sítio. $\mathrm{Na}$ segunda, suspende-se o direito para fundar um novo direito, como nas experiências do poder constituinte. Nesse momento, Agamben (2004) aborda o pensamento de Schmitt, pois a ditadura soberana é o poder fático, político, decisório, com poder e com força que, desde uma decisão, mesmo negando o direito, funda e constitui um novo direito.

A partir do jogo da diferença do estado de exceção, os dualismos metafísicos opostos e irredutíveis acabam sendo articulados e mantendo a máquina do direito funcionando, exatamente como vimos no mix metafísico do sentido comum teórico dos juristas. Em outras palavras, no jogo da diferença do estado de exceção, cria-se, a partir da separação e autonomia entre os momentos da norma e de sua aplicação, justamente as condições teóricas da aplicação. Em conclusão, a máxima oposição torna-se, no jogo diferença, íntima coesão e unidade teórica. Isso somente é possível porque o direito, ao referir-se à realidade, suspende essa realidade, apreendendo-a desde um pressuposto teórico.

O exemplo jurídico do estado de exceção é comparado, por Agamben, com o exemplo da linguagem e sua relação com a realidade. Da mesma forma que o direito, a partir do jogo da diferença do estado de exceção, a referência do semiótico (significante e significação) à realidade denotativa (semântica) é, ao mesmo tempo, a suspensão da realidade, que passa a ser apreendida apenas desde um pressuposto teórico. Assim, a máxima oposição torna-se, no jogo da diferença, íntima coesão e unidade teórica. A principal consequência desses dualismos é que a aplicação no direito e o discurso na linguagem passam a ser analisados apenas teoricamente (com-e-sem as referências à realidade), exatamente como vimos nos tópicos anteriores, quando o direito esquecia, separava e abandonava sua dimensão prática, aplicativa, interpretativa e existencial.

Em polêmica com Kant, Agamben (2004) defende que não se resolve o dualismo direito e realidade, linguagem e realidade ou geral e particular de forma lógica desde o juízo teórico. Nem o juízo reflexivo, que encontra a norma para o caso, e nem o juízo determinante, subsumir o caso na norma, são formas adequadas de resolver a distância metafísica entre os dois mundos. Agamben denuncia em Kant, de um lado, a aporia de decidir concretamente 
entre os dois tipos de juízos e, por outro, a desconfiança de Kant quanto ao exemplo como caso de uma norma que não é possível enunciar. Logo, citando Gadamer, o autor conclui que a passagem do direito e da linguagem à realidade é uma ação prática, uma práxis da aplicação.

Logo, Agamben (2004) defende que, no caso da linguagem, a práxis da aplicação envolve um assumir da linguagem pelo sujeito na função enunciativa. E, no caso do direito, a práxis da aplicação é ação de sujeitos no processo na função enunciativa da sentença que se refere à realidade pelos poderes instituídos. Assim, tanto no direito, como na linguagem, vistos a partir da práxis da aplicação, torna-se impossível a referência suspensiva do estado de exceção à realidade, tornando o jogo da diferença não mais (epistemo) lógico, mas sim ontológico, existencial, prático, do mesmo modo que as propostas existenciais da ciência jurídica.

A referência de Agamben a Gadamer expressamente na sua obra "Estado de exceção" (2004) e as referências a Heidegger em outras obras (2006) indicam que a hermenêutica existencial está presente no todo de seu pensamento. No entanto, a referência a Gadamer é muito marginal e isolada, sem maiores detalhamentos. Mesmo assim, a comparação da finalidade de Agamben no uso da hermenêutica existencial com os exemplos da fecundidade de tal referencial filosófico, nota-se que todos destacam os aspectos destrutivos daquilo que a tradição esqueceu, em nome da abertura de possibilidades construtivas de recolocação e de rememoração de questões que, ao contrário das pretensões científicas e metafísicas tradicionais, estarão sempre preservadas no seu mistério (abertura, verdade, diferença ontológica e círculo hermenêutico).

\section{HERMENÊUTICA JURÍDICA ENTRE EXCEÇÃO E APLICAÇÃO}

Para finalizar a reflexão, exploram-se, como resultados de todas as partes anteriores, dois conceitos: (1) hermenêutica jurídica da exceção e (2) hermenêutica jurídica da aplicação. Para o primeiro, são apresentadas duas obras de Streck, prioritariamente "Verdade e consenso" (2017) e, de modo complementar, "Hermenêutica e jurisdição" (2018). Nessas duas obras, aparece o conceito de "estado de natureza e de exceção hermenêutico", que iremos detalhar. Para o segundo conceito (hermenêutica jurídica da aplicação), apresentam-se as ideias de Gadamer sobre a aplicação. 
Verbicaro (2019) afirma existir vários modelos hermenêuticos e, dentro de cada um, classifica os vários tipos de positivismo, que, para o que interessa aqui, são os seguintes: modelo dedutivo (positivismo exegético, positivismo utilitarista), modelo decisionista (positivismo fático) e modelo discricionário (positivismos de Austin, Kelsen e Hart). As obras de Streck $(2017 ; 2018)$ complementam a classificação anterior com a crítica de Dworkin ao positivismo e as respostas geradas, que acabaram orginando os positivismos inclusivo e exclusivo. No entanto, o objetivo da análise filosófica dos positivismos de Streck é reconhecer o que eles têm em comum: a discricionariedade, que é exemplificada pelo conceito de estado de natureza ou de exceção hermenêutico.

Streck reconhece que toda a tradição da ciência jurídica, não apenas a moderna positivista, está repleta de dualismos metafísicos e científicos que levam ao estade de exceção discricionário. Por exemplo, os dualismos teoria e prática, direito e moral, sujeito e objeto, validade e faticidade, questão de direito e questão de fato, texto e norma, etc. Como vimos nos tópicos anteriores, tais dualismos criam uma distância abissal entre os dois mundos, que é capaz de ser trilhada apenas pelo método, pela teoria, pelos juízos, mas que acabam esquecendo, excluindo e abandonando um dos elementos do dualismo, no caso do direito, a prática, a realidade, o mundo, a existência, a vida.

As consequências de tais dualismos são muitas. A mistura metodológica para superar a distância entre os dois mundos também é evidente, pois, como é sabido, a maioria dos manuais de direito, após apresentarem a enorme quantidade de métodos hermenêuticos, é unânime em afirmar que, apesar da diferença, todos eles são complementares, como se fossem um mix à disposição do intérprete. No entanto, fica o problema das regras das regras da interpretação ou, como afirma Agamben ao criticar Kant, o problema da aporia do juízo que decide qual dos juizos é melhor para o caso particular. Também é reconhecida e notória a mixagem teórica brasileira na recepção de teorias estrangeiras, que, muitas vezes, é feita de modo carnavalesco e miscigenador, mais uma vez como um mix à disposição. Outra consequência é a in-distinção entre jurídico e político, por exemplo, seja em qualquer decisão política (na dúvida se é ou não jurídica), seja em qualquer decisão jurídica (na dúvida se é ou não política), muito presente nos debates do ativismo judicial e judicialização da política.

Para combater todo esse contexto positivista, discricionário e repleto de sincretismos e mixagens do estade de exceção hermenêutico, Streck apresenta uma proposta, que é a crítica hermenêutica do direito, criada na obra "Hermenêutica jurídica e(m) crise" (2014) e 
aprofundada na obra "Verdade e consenso" (2017). Tal proposta tem como fundamento a hermenêutica existencial de Heidegger e Gadamer e recupera, a partir do logos hermenêutico, a dimensão prática, fática e concretizadora do direito, unicamente possível a partir da compreesão e da aplicação. Aqui, há uma proximidade enorme entre as propostas de Streck, Martins e Agamben, todas fundamentadas em Gadamer, e que chamamos de hermenêutica jurídica da aplicação.

A proposta de Streck torna-se completa porque, ao mesmo tempo em que respeita as bases antropológicas da ciência jurídica com sua hermenêutica existencial que recupera o mundo prático do logos hemenêutico, conecta-o com o logos apofântico enquanto momento epistemológico da hermenêutica (2017). Assim, toda a carga prática, fática e existencial do caso, da realidade, é respeitada pelo logos hermenêutico comprensivo, mas, ao mesmo tempo, sem excluir a explicitação de tal compreensão na resposta correta institucional ao caso. Não por acaso, Streck propõe sua teoria da decisão como esse logos apofântico explicitador do logos hermenêutico. A completude de tal proposta não pode ser mais clara quando afirma ser a Constituição um existencial (2004)!

A hermenêutica jurídica da aplicação ampara-se no conceito de aplicação de Gadamer. A compreensão, para Gadamer (1997), nada mais é do que o encontro do horizonte histórico com o horizonte do presente realizado na fusão de horizontes. Nisso, exatamente, reside o problema hermenêutico da aplicação presente em toda a compreensão. A hermenêutica jurídica é paradigmática exatamente no sentido de que em toda interpretação está presente a aplicação, pois o sentido da lei somente se apresenta na compreensão enquanto fusão de horizontes.

Logo, se o intérprete quiser entender um texto, ou seja, compreender o que a tradição diz sobre o sentido do texto, deve, por um lado deixar que o texto e a tradição lhe digam algo e, por outro, não deve ignorar sua situação hermenêutica presente, a qual exige aplicação. Para exemplificar o que afirma sobre aplicação, Gadamer (1997), além de comparar a aplicação com a prudência aristotélica, compara também o historiador do direito com o jurista em suas diferentes pretensões histórica e dogmática. Para Gadamer, ambos trabalham com a mesma situação hermenêutica da aplicação no sentido de que há uma distância entre o horizonte do sentido originário normativo e o horizonte do sentido atual do caso, da situação. 
Portanto, conclui Gadamer (1997), a pertença à tradição é condição da compreensão e momento imprescindível da aplicação na hermenêutica jurídica. Assim, toda interpretação jurídica consiste, nada mais e nada menos, do que concretizar a lei em cada caso, numa palavra, aplicação. Gadamer explica a diferença entre dogmática e hermenêutica, exatamente no mesmo sentido que Streck diferenciando o logos hermenêutico e o logos apofântico, afirmando que, mesmo que a dogmática fosse perfeita no seu conhecimento teórico da lei, nunca iria substituir a primazia que a hermenêutica tem enquanto compreensão prática, aplicativa e concretizadora.

Para Gadamer (1997), a verdadeira concretização do direito, no mesmo sentido que vimos em Agamben, se dá na sentença. A complementação produtiva que o juiz faz do direito ocorre com responsabilidade política, uma vez que o mesmo se encontra subordinado à lei como qualquer outro da comunidade, nunca estando completamente livre frente ao texto. Nesse momento, Gadamer faz uma comparação entre a hemenêutica jurídica e a hermenêutica teológica de Bultmann. A conclusão é a de que qualquer interpretação científica do direito ou da teologia nunca deve esquecer, excluir ou abandonar sua dimensão compreensiva, hermenêutica, prática, numa palavra, existencial.

Contra toda e qualquer pretensão de tornar nossa relação com o texto e com a tradição uma relação lógica, metodológica, científica e teórica com exclusão da aplicação, da existência e do tempo, Gadamer (1997) lembra que toda a tarefa hermenêutica consiste justamente em recuperar como condição de possibilidade de todo sentido a relação de ontem com hoje, do tu e eu, que ocorre na aplicação. Compreender é concretizar. Compreender é aplicar. Compreensão é fusão de horizontes. Logo, a experiência e a situação hermenêuticas são sempre práticas, no sentido de que, na fusão de horizontes na história efeitual, é sempre aplicação. Logo, é sempre hermenêutica jurídica da aplicação.

Para Agamben (2004), há no direito sempre uma fratura essencial e ambígua entre a norma e sua aplicação, preenchida pelo estado de exceção. Nos extremos dessa fratura, há, por um lado, o estado perfeito de direito, em que tudo é regulado, e, por outro, o estado inverso anômico em que nada é regulado. No meio, mais uma vez, a exceção. No cambate à fratura da exceção, ele propõe uma práxis da aplicação. Também para Gadamer há a mesma cisão entre o conhecimento do sentido de um texto jurídico e sua aplicação. No cambate à cisão, Gadamer propõe o processo unitário da aplicação. Assim, o próprio Agamben passa de uma hermenêutica jurídica da exceção para a hermenêutica jurídica da aplicação, o que se 
repete nas propostas que vimos da ciência jurídica em conexão com a hermenêutica existencial.

\section{CONCLUSÃO}

Três são as nossas principais conclusões. A primeira é a de que a crítica hermenêutica do direito se apropria do conceito de estado de exceção para denunciar a discricionariedade como ponto em comum dos positivismos jurídicos.

A segunda é a de que o estado de exceção se apropria da hermenêutica ao refletir sobre a relação entre norma e aplicação. No entanto, em Agamben há, como terceira conclusão, a presença não apenas de uma hermenêutica da exceção, mas também de uma hermenêutica da aplicação. O ser humano, tal como Hermes - e seja como político ou como jurista - deve, em cada instante em que se depara com o limbo, agir/decidir ou interpretar a ação/decisão de outros desde a exceção ou a aplicação!

A hermenêutica da aplicação une as reflexões do estado de exceção com a crítica hermenêutica do direito, pois seu ponto de contato é o conceito de aplicação de Gadamer, que recupera para o direito as experiências de verdade esquecidas, excluídas e abandonas pela metafísica (onto-teo-tecno-lógica entificadora), dentre elas a dimensão prática e existencial da vida, do mundo e do tempo.

\section{REFERÊNCIAS}

AGAMBEN, Giorgio. Estado de exceção. São Paulo: Boitempo, 2004.

AGAMBEN, Giorgio. A linguagem e a morte: um seminário sobre o lugar da negatividade. Belo Horizonte: UFMG, 2006.

AGAMBEN, Giorgio. L’invenzione di un'epidemia. Quodlibet. Disponível em:

<https://www.quodlibet.it/giorgio-agamben-l-invenzione-di-un-epidemia>. 26 de fevereiro de 2020. Tradução em: <http://www.ihu.unisinos.br/78-noticias/596584-o-estado-de-excecao-provocado-por-uma-emergenciaimotivada $>$.

BETTI, Emilio. Interpretação da lei e dos atos jurídicos: teoria geral e dogmática. São Paulo: Martins Fontes, 2007.

BORNHEIM, Gerd Alberto. Introdução ao filosofar: o pensamento filosófico em bases existenciais. 11.ed. São Paulo: Global, 2003.

BULTMANN, Rudolf Karl. Demitologização: coletânea de ensaios. São Leopoldo: Sinodal, 1999.

DILTHEY, Wilhelm. Introdução às ciências humanas: tentativa de uma fundamentação para o estudo da sociedade e da história. Rio de Janeiro: Forense, 2010.

EBELING, Gerhard. Dio e parola. Brescia: Queriniana, 1969.

EILENBERGER, Wolfram. Tempo de mágicos: a grande década da filosofia (1919-1929). São Paulo:

Todavia, 2019.

FOUCAULT, Michel. Nietzsche, Freud e Marx. Porto: Anagrama, 1980.

Rev. de Argumentação e Hermenêutica Jurídica | e-ISSN: 2526-0103 | Evento Virtual | v. 6 | n. 1 | 
FUCHS, Ernst. Ermeneutica. Milão: Celuc, 1974.

GADAMER, Hans-Georg. Verdade e método I: traços fundamentais de uma hermenêutica filosófica. 5.ed. Petrópolis: Vozes, 1997.

GIBELLINI, Rosino. A teologia do século XX. São Paulo: Loyola, 1998.

HEIDEGGER, Martin. Ser y tiempo. Madrid: Trotta, 2003.

HEIDEGGER, Martin. Introducción a lafilosofía. Madrid: Cátedra, 1999.

HEIDEGGER, Martin. Conferências e escritos filosóficos. São Paulo: Nova Cultural, 2000.

HIRSCH, Eric D. Validity in interpretation. Connecticut: Yale University Press, 1967.

KAHLMEYER-MERTENS, Roberto S. 10 lições sobre Gadamer. Petrópolis: Vozes, 2017.

LAWN, Chris. Compreender Gadamer. Petrópolis: Vozes, 2007.

MARTINS, Ricardo Evandro Santos. Ciência do direito e hermenêutica. Campinas: Phi, 2018.

PALMER, Richard. Hermenêutica. Lisboa: Edições 70, 2018.

RICOEUR, Paul; JAPIASSÚ, Hilton Ferreira. O conflito das interpretações: ensaios de hermenêutica. Rio de Janeiro: Imago, 1978.

SCHLEIERMACHER, Friedrich. Hermenêutica: arte e técnica da interpretação. Petrópolis: Vozes, 1999.

SCHMIDT, Lawrence K. Hermenêutica. Petrópolis: Vozes, 2012.

STEIN, Ernildo. Compreensão e finitude: estrutura e movimento da interrogação heideggeriana. Ijuí:

Unijuí, 2011.

STEIN, Ernildo. Introdução ao pensamento de Martin Heidegger. Porto Alegre: Edipucrs, 2002.

STRECK, Lenio Luiz. Hermenêutica jurídica e(m) crise: uma exploração hermenêutica da construção do direito. 11.ed. Porto Alegre: Livraria do Advogado, 2014.

STRECK, Lenio Luiz. Verdade e consenso: constituição, hermenêutica e teorias discursivas. 4.ed. São Paulo: Saraiva, 2017.

STRECK, Lenio Luiz. Jurisdição constitucional e hermenêutica: uma nova crítica do direito. 2.ed. Rio de Janeiro: Forense, 2004.

STRECK, Lenio Luiz. Hermenêutica e jurisdição: diálogos com LenioStreck. Porto Alegre: Livraria do Advogado, 2018.

TATIÁN, Diego. Desde lalinea: dimensión politica en Heidegger. Córdoba: Alción, 1997. 